\title{
The Impact of Face-To-Face Tutorials on College of Education Students: A Case of Unisa's Ekurhuleni Regional Service Centre
}

\author{
Lesiba Molepo \\ University of South Africa, Ekurhuleni Regional Service Centre, \\ Corner R51 \& Brazil Street, Daveyton, 1520, South Africa \\ Emailımolepo@unisa.ac.za \\ Hector Mothudi \\ University of South Africa, Ekurhuleni Regional Service Centre, Corner R51 \& \\ Brazil Street, Daveyton, 1520, South Africa \\ Email hmothudi@unisa.ac.za
}

Doi:10.5901/mjss.2014.v5n20p1928

\begin{abstract}
The aim of the study was to evaluate the impact of face-to-face tutorials on 1st semester 2011 College of Education (CEDU) students at Unisa's Ekurhuleni Regional Service Centre. A case study involving quantitative document analysis was conducted. Attendance registers were used to determine attendance patterns, and examination results to establish students' performance. It was revealed that most students started attending tutorials, but stopped attending subsequently. However, it was also revealed that students who attended tutorials passed their examinations, leading to the conclusion that tutorials make a positive contribution. The researchers recommend that the marketing of tutorial programmes should be intensified. They further recommend constant communication between lecturers, tutors and coordinators. The final recommendation is that ongoing joint or parallel research projects, especially between regional staff, tutors and lecturers be carried out to investigate the impact of all learner support services.
\end{abstract}

Keywords: open and distance learning; face-to-face-tutorials; tutor; learner support.

\section{Introduction and Background}

The University of South Africa (Unisa) has been offering face-to-face tutorials for a number of years in order to support its students. However, not all students enrol for these tutorials, and those who do enrol tend not to attend sessions regularly, seemingly due to the lack of appreciation of the impact of this service. Prinsloo (2010:5) reports that learner support at the University of South Africa (Unisa) is provided by a range of stakeholders and takes the form of academic, affective and administrative support to students. Sonnekus, Louw and Wilson (2006:48) state that during the 1990s Unisa incorporated tutorial practices into its learner support design. In general, students do not seem to know much about faceto-face tutorials and therefore do not enrol for them. Although attendance of tutorials is not compulsory, and tutorials are regarded as supplementary rather than prescribed (Price, Richardson, \& Jelfs, 2007:2), they nevertheless make an important contribution to supporting learner progress through self-instructional materials (Fung \& Carr, 2000:35).

We have noted that some Unisa lecturers do not seem to know much about face-to-face tutorials, and that even if they do, they appear to dedicate insufficient time to supporting and involving their tutors. We have encountered questions from some lecturers such as, "Who are these tutors and who appoints them?" These questions suggest that some lecturers' roles end following their approval of a tutor appointment. The main responsibility for tutor support appears to rest with the Academic Departmental Tutor Coordinator (ADTC). ADTCs are lecturers based in academic departments whose role it is to facilitate liaison between tutors, regional staff and lecturers in their academic departments. We therefore felt a need to conduct this study in order to share the influence of face-to-face tutorials with all stakeholders. The study reported on here focused specifically on face-to-face tutorial services within the College of Education (CEDU).

\section{Theoretical Framework}

One of the authors of social constructionism (Burr, 2003:5) argued that knowledge and social action go together. Face-to- 
face tutorials allow students to interact with their peers and tutors for the purpose of learning. During this process, they create their perceptions of reality together (Burr, 2003:5). Sweeney, O'Donoghue and Whitehead (2004) explain that students are expected to prepare for the tutorial and contribute their thoughts freely in a round table discussion. It is hoped that in this way students who attend tutorials will, together with their peers and tutors, engage with the study material in order to derive maximum benefit from it. The social constructivist approach therefore seemed relevant as a theoretical framework of this study. This approach views learning as a social process whereby meaningful learning occurs when individuals are engaged in social activities (Jackson, Karp, Patrick \& Thrower, 2006). Given that students engage with their study material both in and outside class, they are expected to give real examples and relate their studies to real-life experiences. At Unisa, six or seven tutorial sessions each lasting two or three hours is scheduled per module for students to attend. This arrangement creates opportunities for contact between students and the teaching system whereby questions can be asked and answered, advice provided and moral support given whenever needed (Trindade, Carmo, \& Bidarra, 2000:10). In that way, knowledge is constructed through many social settings that make up students' lived experiences (Jackson et al., 2006). Jackson et al. (2006) further note that social constructivism emphasises language (communication) as the enabling mechanism through which students make sense of their world, both individually and socially, and constantly negotiate and re-negotiate their understanding of their world.

\section{Rationale}

The Higher Education Quality Committee (HEQC) progress report recommended investigation into the effectiveness and sustainability of the tutorial system in terms of supporting students in achieving expected learning outcomes (Unisa, 2011:20). In response to this recommendation, Unisa came up with the commitment below as part of its strategic plan:

Unisa is committed to the continual improvement of the quality of its activities and achievements to fully realise its vision and mission to deliver a unique and quality student learning experience. The main challenge is to generate a culture of quality and transparency within the institution. The development of a strong quality culture - shared by the academic leadership; professional, academic and administrative support staff, and students - is an on-going [sic] process (Unisa, 2011:5).

It is within this context that the researchers embarked on a study to evaluate the impact of face-to-face tutorials on 1st semester 2011 CEDU students at Unisa's Ekurhuleni Regional Service Centre (UERSC). In order for Unisa to continue rendering effective face-to-tutorial services, it is important that attention be paid to the effectiveness of the monitoring and evaluation system, as stated by UNESCO (2003) below:

The success of any distance education institution, dual or single mode, is highly dependent on the efficiency and effectiveness of the monitoring and evaluation system, without which it may be impossible for administrators to be aware of problems in the system until the system itself breaks down.

We considered it important to rely not on informal, unstructured feedback (UNESCO, 2003) regarding the effectiveness of the face-to-face tutorial service, but rather on a scientific study such as this one. Evaluating this particular student support service would assist regional staff in particular and Unisa in general to identify possible shortcomings and make the necessary adjustments. Brindley and Paul (2004:45) underscore the relevance of a study such as this one by stating that an effective student support service in open and distance learning (ODL) "evolves continuously to accommodate new learner populations, educational developments, economic conditions, technological advances and findings from research and evaluations". The results of this study will also provide lecturers with insight as to how this service adds value to their teaching strategies. Given that evaluation studies have consequences for who gets what in society as suggested by Simons (2009:22), the university management will also obtain information that will enable them to decide whether to continue with this service, and if so, in what format.

\section{Problem Statement}

Although face-to-face tutorials have been offered for a number of years at a minimal cost per module at Unisa (Sonnekus et al, 2006:48), for a number of reasons some students simply do not enrol. With effect from 2013, Unisa decided to offer these tutorials free of charge. A possible reason for non-enrolment is that students are unaware of the immediate benefits of this service. Some students enrol for tutorials only after they have failed the module, which makes tutorials a remedial support mechanism - in other words, tutorials are regarded as a last resort. Given that face-to-face tutorials were offered on the basis of a minimum number of students per regional centre (Prinsloo, 2010:8), it proved difficult for regional staff and tutors to offer tutorials for some modules. Some students enrolled much earlier with the hope that their fellow students would follow suit so that tutorials could commence. However, in some cases student numbers do not reach the 
required minimum, and consequently the tutorials are not offered. It was interesting to note that if tutorials commenced with a small number of students and short message service (SMS) messages are sent to students about scheduled tutorial classes, only then do more students arrive to enrol. It must also be noted that even after students received SMS notifications, there are still those who are left out due to the enrolment cutoff date. This pattern persists even though students are informed about a range of services, including tutorials, during student orientation sessions.

Some students enrol, but do not attend classes as regularly as they should. There are those who tend to attend a few sessions in the beginning, stop attending, and reappear towards the examination period in the hope of receiving information that will help them pass examinations. Such inappropriate expectations undermine an opportunity to fully explore the benefits of tutorials as per social constructivism theory. Irregular attendance defeats the purpose of tutorials, which is to give students the basics of specific modules and prepare them for independent learning. Bliuc, Ellis, Goodyear and Piggott (2010:522) advanced the view that students who approach discussions, such as those engaged in face-toface tutorials, as a way of deepening their understanding of the topic seem to achieve better academically. Nonattendance (or irregular, minimal attendance) may have a negative impact on students' results in particular.

\section{The Aim of the Study}

Fouché and De Vos (2005:104) define "the goal, purpose or aim as the 'dream'; and the objective as the steps one has to take, one by one, realistically at grass-roots level, within a certain time span in order to attain a dream". The aim of the study reported on was to evaluate the impact of face-to-face tutorials on 1st semester 2011 CEDU students at UERSC. The objectives of the study were:

- to evaluate tutorial attendance patterns of 1st semester 2011 CEDU students.

- to evaluate how attendance of tutorials contributed to the performance of 1st semester 2011 CEDU students.

\section{The Research Question}

One of the questions Jansen (2007:7) suggests that the researcher asks in order to develop a research question is: "Does the existing research speak to my context?" Given that we, the researchers, are based at UERSC, the research question shaping the study reported on here therefore is: How did attendance of face-to-face tutorials contribute to the performance of 1st semester CEDU 2011 students at UERSC?

\section{Research Methodology}

The form of research undertaken was evaluation research, which sought to determine whether a social intervention has produced the intended results (Babbie, 2010:363). The research fell within the quantitative paradigm, and we dealt with data that was already available. Johnson and Onwuegbuzie (2004:19) state that quantitative research is useful for obtaining data that allows quantitative predictions to be made. We predicted that students who registered for face-to-facetutorials and attended sessions regularly would pass their final examinations. It was our intention to make predictions about those students who will register for face-to-face tutorials in future. The study therefore took the form of an explanatory research case study.

Yin (2009:4) asserts that "the more the questions seek to explain some present circumstance, and the more the question requires extensive and 'in-depth' description of some social phenomenon", the case study would be relevant. A case study is a research strategy which focuses on understanding the dynamics present within single settings (Eisenhardt, 1989:534). Hence we have decided to focus on UERSC in order to gain a closer understanding of the impact of tutorials at the regional centre where we were based. According to Simons (2009:22), an evaluation case study needs to discern the value of the programme. We were interested in the impact of the services rendered at UERSC, and did not necessarily study a case to understand other cases, but rather a specific case (Stake, 1995:4).

\subsection{Sampling}

Purposive sampling was used in that we intended to include a predetermined type of student in the study (Kumar, 2011:207). The research population consisted of all students attending face-to-face tutorials at UERSC. The target population, however, was all those students who enrolled to attend CEDU tutorials at UERSC during the 1st semester of 2011. A total of 108 students recorded on the Citrix student system portal (CTX) as having been enrolled for tutorials for these modules were therefore included in this study. Their individual information was thoroughly scrutinised in order to 
understand how the actions of a single person or persons contribute to an understanding of the case (Simons, 2009:70).

Purposive sampling was also used to identify the modules to be included in the study. The following four modules falling under CEDU were identified: (1) The Learning Child (ETH102L), (2) Child Development (EDT1601), (3) Learning and Teaching Strategies (EDT1602) and (4) Guidance and Counselling (EDT102H). These were the only modules falling under the CEDU for which face-to-face tutorials were offered. We therefore used purposive sampling, in that a sample was chosen on the basis of what we considered to be typical units (Bless, Higson-Smith \& Kagee, 2006:106).

\subsection{Data collection method}

Information pertaining to students who have enrolled for face-to-face tutorials is captured on the Unisa official student system, CTX. We accessed and printed information pertaining to all students who enrolled for all four CEDU modules in order to scrutinise these "available", "stable", and "rich" records (Lincoln \& Guba, 1985:276-277).

The Directorate: Instructional Support Services (DISS) prescribes in terms of its operational practices and procedures that the names of all students who attended face-to-face tutorial classes should be captured on CTX-F209. This must be done as soon as possible, preferably on a Monday following the weekend in which tutorial classes have been offered. We retrieved these attendance registers as part of data collection in order to establish patterns of attendance for individual students.

The second source of data (examination results) was also printed from the student system. These documents contained "exact information" (Yin, 2009:102) in that they contained the names of students, the dates on which they attended tutorial sessions, and their examination results.

\subsection{Analysis and discussion of results}

The main aim of analysis was to establish potential patterns and meaning from this data. We first edited the data, and analysed the information manually. During the data collection process, we were able to see patterns emerging. Monette, Sullivan, and DeJong (2008:364) view statistical analysis as procedures for assembling, classifying, tabulating and summarising numerical data information. As we moved towards closer analysis of each student's information, we discovered that we could not access the examination results of 23 students, as these students had study fees outstanding: as a result, in the graphs presented below, there is a 'no results' item. When calculating the pass percentage, we therefore excluded those whose examination results were inaccessible. It must be noted that answers to our questions were found through interpreting the data and the results (Fouché \& Bartley, 2011:249).

The first module to be analysed was ETH102L. Figure 1.1 below illustrates the performance of students in terms of pass rate.

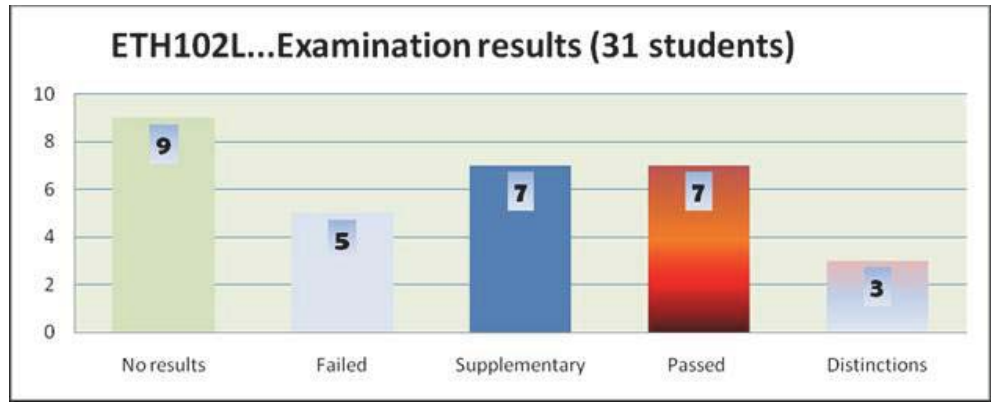

Figure 1: ETH102L...Examination results

As shown in figure 1, of 31 students, 10 obtained an outright pass (passed and distinction). Only five students failed. We were unable to access the results of nine students. Nevertheless, it must be noted that the pass rate for this particular module was $45 \%(10 / 22 \times 100=45 \%)$. This percentage in the researchers' view is not impressive. It therefore had to be scrutinised in relation to figures 2 and 3 below which are a representation of students' attendance patterns. 


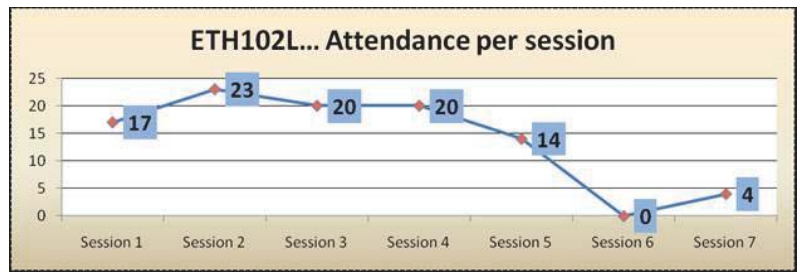

Figure 2: ETH102L attendance per session

Figure 2 shows good initial attendance of more than half of the enrolled students attending the first four sessions. It also indicates that attendance dropped significantly towards the end; less than half the enrolled students attended the last three sessions. The zero attendance of session 6 can be attributed to the fact that the lecturer of this particular module had arranged discussion classes for that particular day, a fact of which regional staff and tutors were unaware. Students informed them a week later that they had not attended tutorial classes because they had been required to attend discussion classes. Figure 3 illustrates the number of sessions attended by individual students.

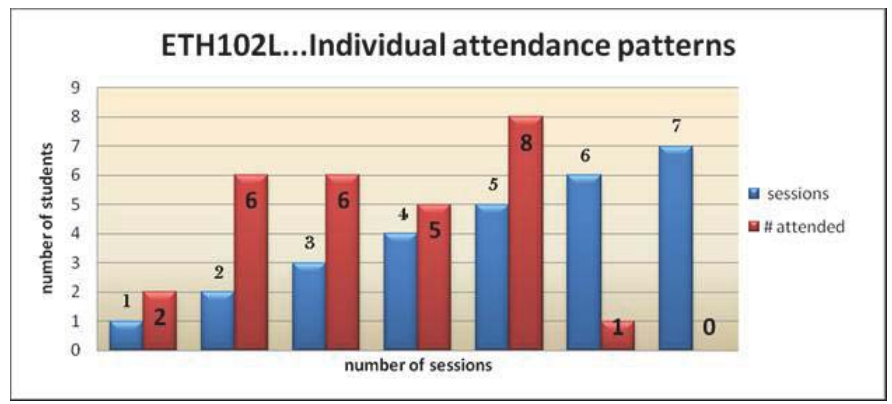

Figure 3: ETH102L individual attendance patterns

Scrutiny of the graph in Figure 3 reveals that two students attended only one session and that only one student attended six sessions. It is also worth noting that eight students attended a total of five sessions. No student attended all seven scheduled sessions.

It is also important to now scrutinise the next module (EDT1602) in figure 4 below and see the patterns that have emerged.

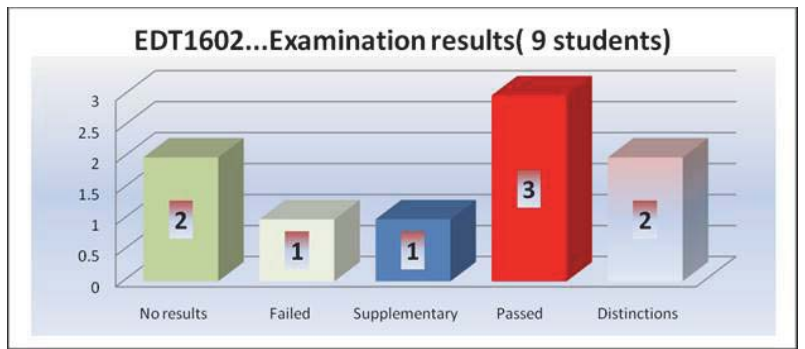

Figure 4: EDT1602...Examination results (9 students).

The EDT1602 examination results as presented in figure 4 above illustrate that we were unable to access the results of only two students. We are of the opinion that this presents a better picture of results than those for ETH102L. According to this graph, a total of five students obtained an outright pass; this represents a pass rate of $71 \%(5 / 7 \times 100=71 \%)$. Although the total number of students enrolled in this module is small, the performance is good as compared to the previous module. It is also important that we scrutinise the attendance patterns of this particular module in figure 5 below. 


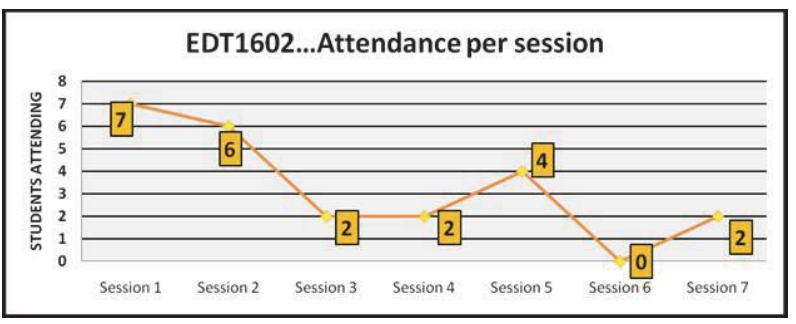

Figure 5: EDT1602 attendance per session

Figure 5 shows attendance patterns for EDT1602. As in the case of ETH102L there was zero attendance of session 6 , also owing to the scheduling of discussion classes on the same day as tutorial classes. Session 7 was also poorly attended, with only two students present. It is also worth noting that attendance was good for the first two sessions and then dropped to two in sessions 3 and 4.

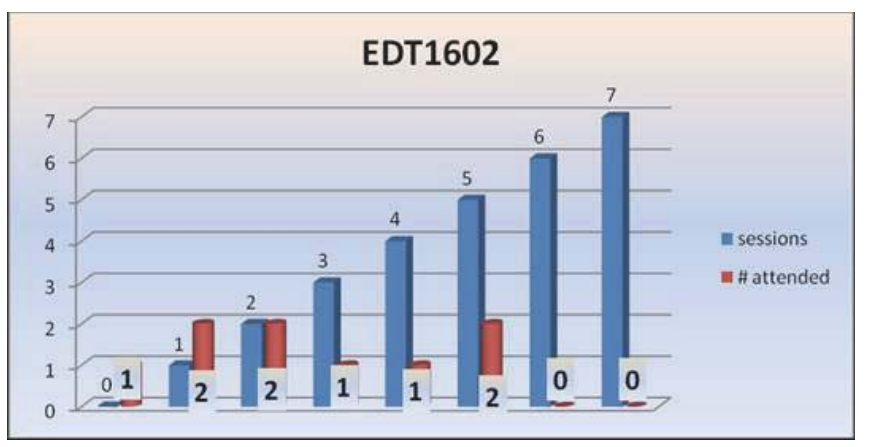

Figure 6: EDT1602 individual attendance patterns

Figure 6 reflects individual students' attendance patterns of EDT1602 and presents an even bleaker picture. One student did not attend a single tutorial session, despite having enrolled and paid to attend. The fact that two is the maximum number of students who attended any particular session is an even more worrying trend. Below is figure 7 which depicts another module. EDT1601, and portrays a completely different picture as compared to the previous two modules.

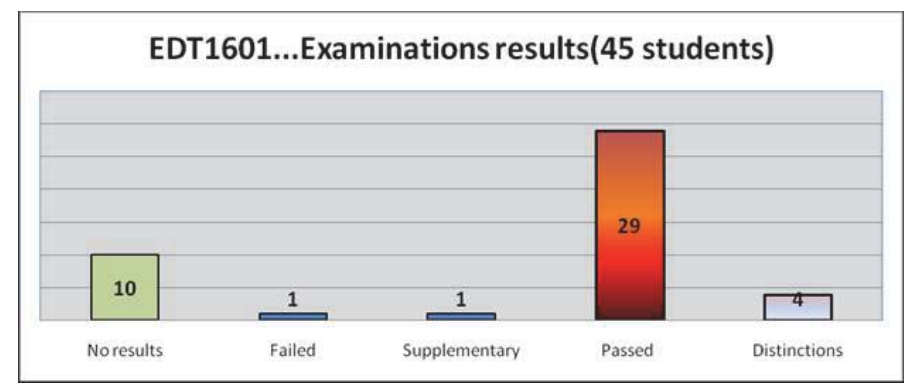

Figure 7: EDT1601...Examination results (45 students).

According to Figure 7 the performance of EDT1601 students is much more positive in that out of 45 students, 33 passed. Despite a significant number of students in the 'no results' column, given that a good number of students enrolled for this module, the results do present a fairly balanced picture. Of the 35 students whose marks were available, 33 obtained an outright pass, which translates into a $94 \%$ pass rate $(33 / 35 \times 100=94 \%)$. Attendance patterns of this particular module as portrayed in figure 8 are also good. 


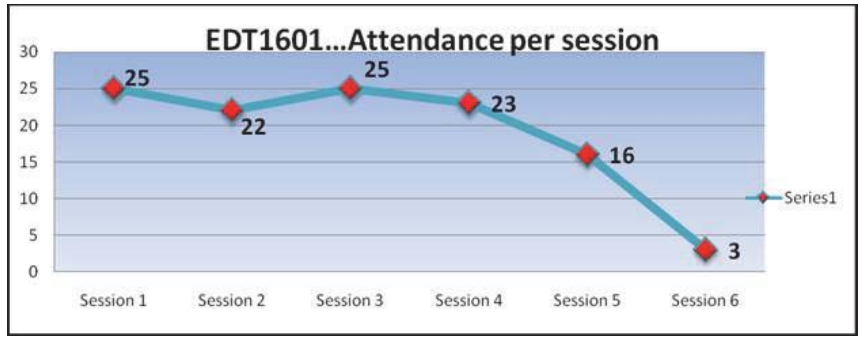

Figure 8: EDT1601...Attendance per session

Figure 8 gives an indication of how students collectively attended tutorial sessions. As in the case of the previous attendance patterns, there is a decline in attendance of the last sessions. The difference though is that only six sessions were scheduled for this module. The reason for having scheduled only six modules was because the researcher was informed by the students about the planned discussion class and cancelled the tutorial session accordingly. The fact that more than half the enrolled students attended the first four sessions may also have contributed to the good pass rate achieved. Individual attendance patterns as captured in figure 9 however present a different picture.

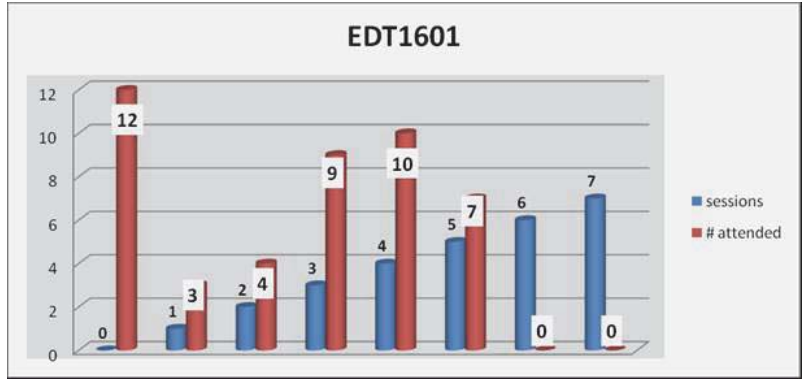

Figure 9: EDT1601 individual attendance patterns

Figure 9 shows the attendance patterns of individual students enrolled for EDT1601. In this particular module, it is significant to note that 12 students did not attend a single session despite having enrolled for face-to-face tutorials and no student attended sessions 6 or 7 at all. This figure also illustrates that 10 students attended a total number of four sessions. The examination results of the final module EDT102H will now be presented in figure 10 that follows:

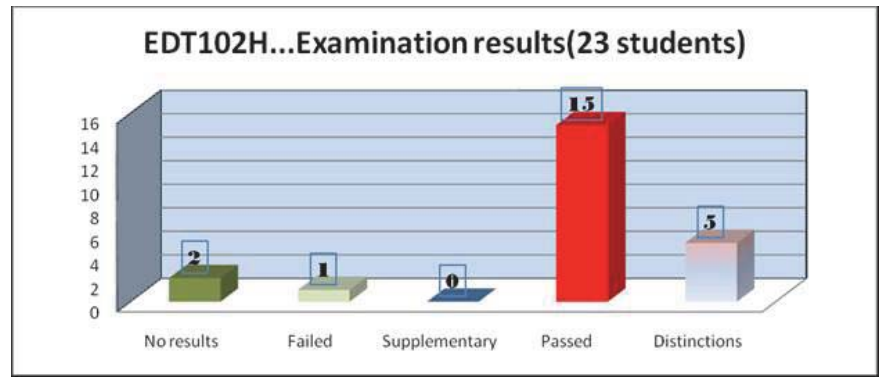

Figure 10:EDT102H...Examination results (23 students).

Figure 10 is an account of the EDT102H examination results obtained by the students. As shown in this paragraph, 20 students obtained an outright pass; this translates into a 95\% pass rate $(20 / 21 \times 100=95 \%)$. What is of significance to interrogate, though, is the attendance patterns of this particular module as it differed significantly from the first three modules discussed above. 


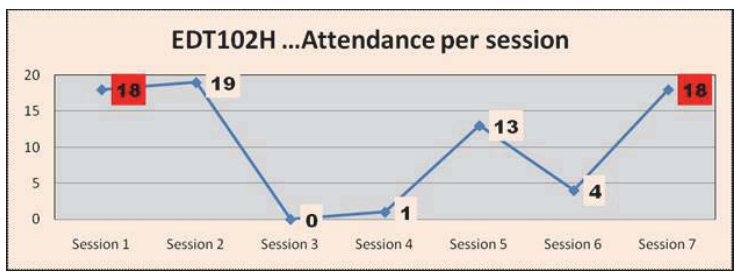

Figure 11:EDT1602 attendance per session.

Figure 11 is an indication of students' collective attendance of EDT102H tutorial sessions. No students attended session 3 , owing to a clash between discussion classes and the tutorial session as was the case with the previous two modules. Of special interest on the above graph is that 18 students attended both session 1 and session 7 . This pattern is in contrast with the attendance patterns of the previous three modules. The pattern nevertheless confirmed the point made earlier that students have a tendency to enrol, disappear and reappear towards the end of the sessions in the hope that they will be given examination information. Figure 12 below clarifies the individual students' patterns of EDT102H.

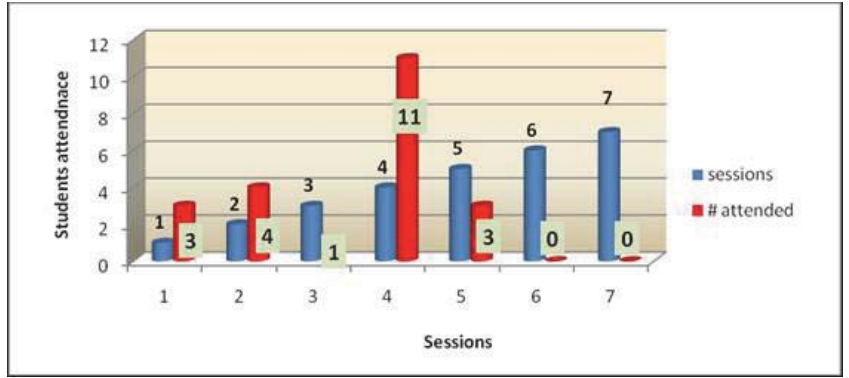

Figure 12:EDT102H individual attendance patterns

Figure 12 above also shows that no student attended more than five sessions. However, the maximum number of students attended four sessions. No student attended six or seven sessions.

\section{Discussion of the Overall Results}

Figure 13 below gives an overall picture of the relationship between students' attendance patterns and their performance.

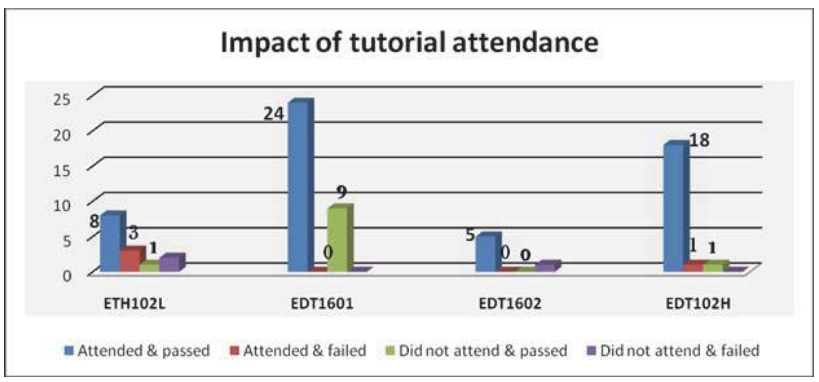

Figure 13:Summary of individual attendance and examination results

In the case of all the modules, the number of students who attended tutorials and passed the module is greater than the number of those who attended and failed and those who did not attend and failed. Attendance patterns were in contrast to what we had expected when drafting the problem statement, namely that students tended to attend the first sessions, disappear, and then reappear towards the time of the examinations (finding). Indeed students tended to attend the first 
few sessions in numbers but never re-emerged. It can therefore be concluded that the tendency to attend tutorials for examination purposes seemed to be less marked, with the exception of EDT102H.

It became evident that students' attendance of tutorials tended to be highest in the middle of the sessions. Given that sessions 3 and 4 were scheduled during the period when most assignments were due for submission, we wondered whether students attended these sessions in order to obtain help with their assignments. The answer could be consonant with Fung and Carr's (2000:41) finding that the most important reason students gave for attending tutorials was to listen to the tutor explaining the course material, followed by receiving guidance on assignments. Another noticeable pattern is that students tended to attend the first few sessions in greater numbers, with attendance declining towards the end. On the one hand, this may be a worrying factor to tutors and regional staff. This pattern can prematurely be interpreted as a sign of dissatisfaction about some components of tutorials such as the tutor's facilitation style as well as the type of content covered during tutorial sessions. On the other hand, considering that Unisa intends to assist students in becoming independent learners, this trend should perhaps not be cause for concern. It must be recognised that more flexibility brings with it more independence, which in turn calls for learners to be more responsible, more self-directed and more self-motivated (Collis \& Moonen in Samarawickrema, 2005:52). We would like to argue that students received the assistance they needed, and developed the self-assurance and confidence necessary to allow them to cope on their own.

The other point we would like to highlight is that unlike tutors responsible for other modules, tutors for CEDU modules have extensive training and experience as facilitators. Fung and Carr (2000:40) argue that tutors trained in particular disciplines and experienced in the related professions would be likely to project their own learning styles during their teaching. Therefore, CEDU tutors may have had an advantage when it comes to facilitating, resulting in good examination results. Jansen (2011) concedes that with the exception of the few who studied and practised teaching, academics, which may include tutors in this case, have no clue how to teach. Although the regional staff train all the tutors whom they appoint, we wondered whether the professional backgrounds of the CEDU tutors have a bearing on their contribution to students' performance and whether the examination results were due to characteristics of these tutors (Price et al, 2007:7). Only further research may shed light into this phenomenon.

\section{Conclusion}

We take cognisance of the fact that there are many variables that contribute to student success. Prinsloo (2010:7) points out that there are many stakeholders offering a wide range of student support services and initiatives to a range of students in diverse contexts and at different times.

As for the examination results for the modules covered in this study, it is evident that students who enrolled for face-to-face tutorials performed well. We therefore conclude that face-to-face tutorials did make a positive impact on 1st semester 2011 CEDU students at UERSC.

\section{Recommendations}

Emanating from the conclusion that face-to-face tutorials make a positive impact on students' performance, we recommend that efforts be made to discourage students from thinking of face-to-face tutorials as an instrument to find answers (as seen in EDT102H attendance per session), as otherwise they will continue to use them in a way that encourages reproduction and task completion rather than meaningful learning (Bliuc et al., 2010:522). Instead, tutorials should be intensely marketed so that from the onset, students view them as a support programme with positive impact on their learning.

We recommend that there be constant communication between lecturers, tutors and regional administrative and support staff. This will be in line with the HEQC recommendations that advocated steps to manage the nature and quality of the interactions between lecturers, coordinators and tutors (Unisa, 2011:7). This communication will allow maximum use of resources as suggested by Prinsloo (2010:8) and avoid or minimise clashes between tutorial classes (offered by tutors) and discussion classes (offered by lecturers).

We further recommend that ongoing joint or parallel research projects, especially between regional staff, tutors and lecturers be carried out to investigate the impact of all learner support services. This approach will ensure constant improvements of all tuition and facilitation of learning support services. Once such research projects are carried out, the results need to be published, not only in academic journals but also in student magazines to allow students to see the benefits of these services. If information is published in a user-friendly manner in student magazines, students may gradually view all support services as an integral part of their learning. They may also begin to refrain from enrolling into some of these services as a remedial measure to overcome their academic challenges. 


\section{Ethical Considerations}

The fact that we had students' data at our disposal did not give us automatic permission to use access and use student information for research purposes. As it would have been too time-consuming to obtain permission from individual students, we notified the Unisa Gauteng Regional Director about our intention to carry out this research. This courtesy came prior to the introduction of the policy that requires all staff to get permission before they can use Unisa data for research purposes which only came into effect in 2012. Nonetheless, all information collected was used solely for the purpose of this research.

\subsection{Confidentiality and anonymity}

All the information obtained about the participants was treated as confidential. Although during the research phase it was necessary to identify students by using their student numbers, we used this information only to confirm attendance patterns and obtain examination results. This information was always kept electronically in a protected file. During the writing up of the report, student numbers and names were deleted in order to protect the identity of the students. Hence this information is not reported anywhere in this article.

\subsection{Delimitation of the study}

We collected students' data based on the modules for which they had enrolled to attend tutorial classes during the first semester of 2011. It was not our intention to evaluate any other modules for which students were enrolled for tutorials. The study therefore focused only on those students who enrolled for and paid to attend tutorials for identified modules.

It is therefore important to note that the results of this study may not necessarily reflect the situation in other Unisa regional service centres. As a result, the findings of the impact of tutorials could be limited to 1st semester 2011 CEDU students at UERSC.

\subsection{Limitations of the study}

The main challenge that we experienced was the inaccessibility of some of the students' examination results owing to outstanding study fees. To overcome this, we approached the relevant Department of Assessment Administration, explaining our intentions and requesting the results of the affected students from them. This approach proved unsuccessful, as we were not given permission to access those results; consequently, those results were recorded 'no results'. The presented results can therefore not present the whole picture in terms of students' performance.

Another limitation is that Unisa students are able and allowed to attend tutorial classes at different centres. When a student attended at a centre other than UERSC, s/he was deemed to have been absent from tutorial classes for the purposes of this study, making it difficult to confirm the actual number of students attending. However, we believe that attendance of tutorials by UERSC students at other centres was minimal.

\section{References}

Babbie, E. (2010). The practice of social research. 12th ed. Belmont: Wadsworth.

Bless, C., Higson-Smith, C. \& Kagee, A. (2006). Fundamentals of social research methods: An African perspective. 4th ed. Cape Town: Juta.

Bliuc, A., Ellis, R., Goodyear, P. \& Piggott, L. (2010). Learning through face-to-face and online discussions: Associations between students' conceptions, approaches and academic performance in political science. British Journal of Educational Technology, Vol. 41, No 3. pp. $512-524$.

Brindley, J.E. \& Paul, R.H. (2004). The role of learner support in institutional transformation - A case study in the making. Available: http://www.c3l.uni-oldenburg.de/cde/support/fa04/Vol.\%209\%20chapters/BrindleyPaul.pdf (Accessed: 2011/12/06).

Burr, V. (2003). Social constructionism. 2nd ed. USA: Routledge.

Eisenhardt, K.M. (1989). Building theories from case study research. Available: http://www.jstor.org/stable/10.2307/258557 (Accessed 2011/12/06).

Fouché, C.B. \& Bartley, A. (2011). Quantitative data analysis and interpretation. In De Vos, A.S., Strydom, H., Fouché, C.B. \& Delport, C.S.L. (eds). Research at grassroots for the social sciences and human service professions. 3rd ed. Pretoria: Van Schaik.

Fouché, C.B. \& De Vos, A.S. (2005). Problem formulation. In De Vos, A.S., Strydom, H., Fouché, C.B. \& Delport, C.S.L.(eds). Research at grassroots for the social sciences and human service professions. 3rd ed. Pretoria: Van Schaik. 
Fung, Y. \& Carr, R. (2000). Face-to-face tutorials in a distance learning system: Meeting student needs. Hong Kong: School of education and languages, Open University of Hong Kong.

Jackson, R., Karp, J., Patrick, E. \& Thrower, A. (2006). Social constructivism vignette. Available: http://relectionandpractice.pbworks. com/f/Social\%20Constructivism.pdf (Accessed 2011/12/05).

Jansen, J. (2007). The research question. In Maree, K. (Ed.). First steps in research. Pretoria: Van Schaik.

Jansen, J. (2011). Teaching academics the art. The Times, 8 December, p. 10.

Johnson, R.B. \& Onwuegbuzie, A.J. (2004). Mixed methods research: A research paradigm whose time has come. Educational Researcher. Vol. 33, No.7, pp.14-26.

Kumar, R. (2011). Research methodology: A step-by-step for beginners. California: SAGE.

Lincoln, Y.S. \& Guba, E.G. 1985. Naturalistic inquiry. Newbury Park, CA: SAGE.

Monette, D.R, Sullivan, T.J. \& DeJong, C.R. (2008). Applied social research: A tool for the human services. $7^{\text {th }}$ ed. Belmont, CA: Thomson Wadsworth.

Price, L.T.E., Richardson, J.T.E. \& Jelfs, A. (2007). Face-to-face versus online tutoring support in distance education. Studies in Higher Education. Vol. 32, No. 1, pp. 1-20.

Prinsloo, P. (2010). Implementing the conceptual framework for student support at Unisa: A proposal for 2011-2013. Pretoria: Unisa.

Samarawickrema, R.G. (2005). Determinants of student readiness for flexible learning: Some preliminary findings. Distance Education. Vol. 26, No. 1, pp. 49-66.

Simons, H. (2009). Case study research in practice. Los Angeles: SAGE.

Sonnekus, I.P., Louw, W.P., \& Wilson, H. (2006). Emergent learner support at University of South Africa: An informal report. Pretoria: Unisa.

Stake, R.E. (1995). The art of case study research. California: SAGE.

Sweeney, J., O'Donoghue, T. \& Whitehead, C. (2004). Traditional face-to-face and web-based tutorials: A study of university students' perspectives on the roles of tutorial participants. Teaching in Higher Education. Vol. 9, No. 3. pp.310 - 323.

Trindade, A.R., Carmo, H., \& Bidarra, J. 2000.-Current developments and best practice in open and distance learning. International review of research in Open and Distance Learning. Vol. 1, No. 1. Available: http://www.irrodl.org/index.php /irrodl/article/view/7/342. Accessed 2014/04/22).

UNESCO. (2003). Components of all distance learning systems. UNESCO Education.

Unisa. (2011). HEQC progress report. Transforming academic and institutional identity for excellence in an ODL university. Pretoria: Unisa.

Yin, R.K. 2009. Case study research: Design and methods. 4th ed. Applied social research methods series, Vol. 5. Los Angeles: SAGE. 